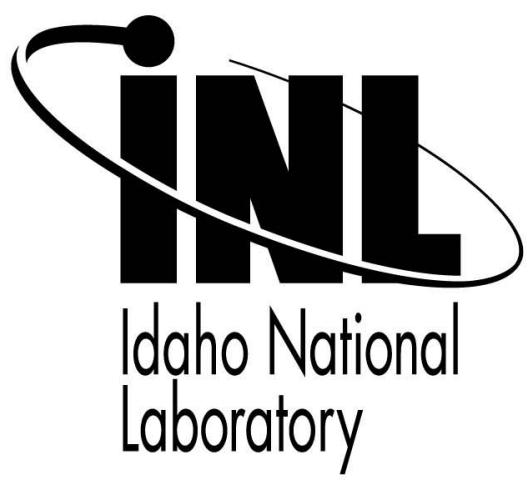

\section{AIAA 4th International Energy Conversion Engineering Conference and Exhibit (IECEC)}

\author{
Kenneth E. Rosenberg \\ Stephen G. Johnson
}

\title{
Assembly and Testing of a Radioisotope Power System for the New Horizons Spacecraft
}

\author{
June 2006
}

This is a preprint of a paper intended for publication in a journal or proceedings. Since changes may be made before publication, this preprint should not be cited or reproduced without permission of the author. This document was prepared as an account of work sponsored by an agency of the United States Government. Neither the United States Government nor any agency thereof, or any of their employees, makes any warranty, expressed or implied, or assumes any legal liability or responsibility for any third party's use, or the results of such use, of any information, apparatus, product or process disclosed in this report, or represents that its use by such third party would not infringe privately owned rights. The views expressed in this paper are not necessarily those of the United States Government or the sponsoring agency. 


\title{
Assembly and Testing of a Radioisotope Power System for the New Horizons Spacecraft
}

\author{
Kenneth E. Rosenberg ${ }^{*}$ and Stephen G. Johnson ${ }^{\dagger}$ \\ Idaho National Laboratory, PO Box 1625, Idaho Falls, Idaho 83403
}

\begin{abstract}
The Idaho National Laboratory (INL) recently fueled and assembled a radioisotope power system (RPS) that was used upon the New Horizons spacecraft which was launched in January 2006. New Horizons is the first mission to the last planet - the initial reconnaissance of Pluto-Charon and the Kuiper Belt, exploring the mysterious worlds at the edge of our solar system. The RPS otherwise known as a "space battery" converts thermal heat into electrical energy. The thermal heat source contains plutonium dioxide in the form of ceramic pellets encapsulated in iridium metal. The space battery was assembled in a new facility at the Idaho National Laboratory site near Idaho Falls, Idaho. The new facility has all the fueling and testing capabilities including the following: the ability to handle all the shipping containers currently certified to ship Pu-238, the ability to fuel a variety of RPS designs, the ability to perform vibrational testing to simulate transportation and launch environments, welding systems, a center of mass determination device, and various other support systems.
\end{abstract}

\section{Introduction}

The production of RPSs has been an on-going endeavor for the Department of Energy (DOE) and its predecessor agencies for the past five decades, including the production of RPS devices for the National Aeronautics and Space Administration (NASA), commonly known as Radioisotope Thermoelectric Generator (RTG). The first device was produced in the late 1950's at the request of the Eisenhower administration.

For each device, the heart of the power source for the devices to be built under this program is a ceramic consisting of sintered plutonium-238 oxide encapsulated in iridium. There are other heat source schemes that will be employed in the future but they will share two basic characteristics:

1. $\mathrm{The}^{238} \mathrm{PuO}_{2}$ material in some form produces the heat, and

2. Enclosed in materials specially designed to enhance safety in space launch environments.

The sintered Pu-238 ceramic is currently produced at Los Alamos National Laboratory (LANL), although the $\mathrm{Pu}-238$ itself is produced elsewhere and is supplied to LANL. This material is attractive in that its radioactive decay produces 0.57 watts $(1.94 \mathrm{Btu} / \mathrm{hr})$ of thermal energy per gram of elemental plutonium-238. This is accomplished with little undesirable radiation in the form of neutrons. The heat produced is either used directly in the form of heat or used to power a converter that produces electricity. The Pu-238 fueled heaters are typically used to warm sensitive instrumentation aboard spacecraft, whereas, the electricity produced from $\mathrm{Pu}-238$ fueled devices is used to conduct extra terrestrial mission specific experiments or analyses. The RPSs use a thermoelectric process to convert the heat to useable electricity.

For extraterrestrial missions, an RPS is used on missions that can not use solar power - yet require a proven, reliable power supply that can produce up to several kilowatts of power and operate under severe environmental conditions for many years.

A special panel of the National Academy of Sciences that was formed to advise NASA on a planetary science strategy for the next decade (the so-called "Decadal Survey") ranked the exploration of Kuiper Belt Objects, including Pluto, as its highest scientific priority. The New Horizons mission is NASA's way to implement that recommendation. New Horizons is designed to help us understand worlds at the edge of our solar system by making the first reconnaissance of Pluto and Charon - a "double planet" and the last planet in our solar system to be visited by spacecraft. Electrical power for the New Horizons spacecraft and science instruments is provided by a single

\footnotetext{
* Kenneth Rosenberg, Idaho National Laboratory, PO Box 1625, Idaho Falls, Idaho 83403

${ }^{\dagger}$ Stephen G. Johnson, Idaho National Laboratory, PO Box 1625, Idaho Falls, Idaho 83403
}

American Institute of Aeronautics and Astronautics 
RPS, assembled and tested at the INL. A complete description of the New Horizons Program is described in Reference (1).

\section{Background}

The United States Department of Energy (US-DOE) had been assembling and testing RPSs at the Mound Site (Mound) in Miamisburg, Ohio, for the past 35 years ending in 2002. Pursuant to a DOE complex-wide safeguards and security review, Mound was identified for the implementation of additional security and safeguards measures. The program at Mound could not be able to bear the cost of these additional measures. Therefore, the DOE decided to relocate the program to another DOE site, which is more cost effective from a security and safeguards standpoint. The DOE conducted a National Environmental Policy Act (NEPA) review to decide the future location of Mound's RPS operations. After consideration of the comments received at the public scoping meetings and analysis of currently available information for the alternatives under consideration, DOE has selected the INL, specifically the Materials and Fuels Complex (MFC), as the site for relocation of RPS assembly and testing operations.

The INL designed and constructed a new facility for the assembly and testing of RPSs. This new facility is knows as Space and Security Power Systems Facility (SSPSF). The new facility, SSPSF, consists of two separate parts that are joined together physically via a breezeway, the older original facility (792) and the new annex (792A). The new addition was constructed to performance category (PC) 3 standards consistent with a DOE nuclear facility hazard category II designation per Reference (2). The choice of the PC 3 rating versus a PC 2 rating, which would be the minimum for a hazard category II facility, was at the discretion of the Department of Energy to safeguard the valuable generator when it is within the building. The two parts of the facility both fulfill vital roles for the mission of the facility, which is assembly and testing of RPS units.

Some assembly and testing equipment was transferred from Mound to the INL. The balance of the assembly and testing equipment was designed, fabricated and installed by the INL.

The first RPS device assembled and tested at the SSPSF was for the NASA sponsored New Horizons Mission. The RPS device used in this mission is a General Purpose Heat Source (GPHS) RTG. Figure 1 shows a cutaway of the generator. For reference, the generator is approximately $1.22 \mathrm{~m} \mathrm{(4ft)} \mathrm{long} \mathrm{and} .457 \mathrm{~m}(1.5 \mathrm{ft})$ in diameter. The GPHS RTG comprises a stacked series of eighteen (18) modules (Figure 2) fueled with plutonium-238 dioxide fuel pellets (Figure 3).

The power requirements set for the New Horizons RTG are listed as follows:

DC power at an output voltage of $30+0.7 /-0.5$ volts as follows:

Beginning of Mission (BOM) Power: $237 \mathrm{~W}$ (minimum)

9 1/2 Years after BOM: $191 \mathrm{~W}$ (minimum).

American Institute of Aeronautics and Astronautics 


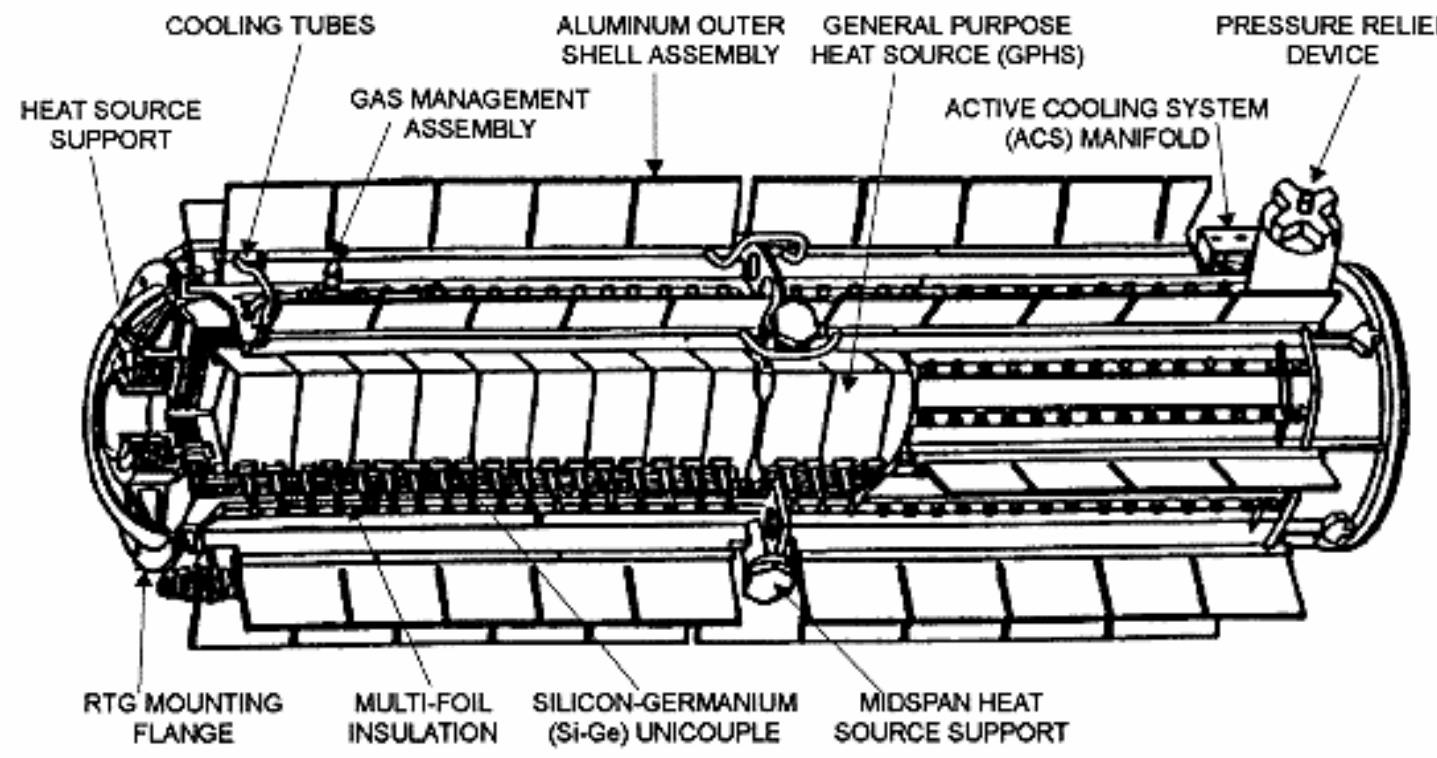

Figure 1. Cutaway of a general purpose heat source (GPHS) radioisotope thermoelectric generator (RTG).

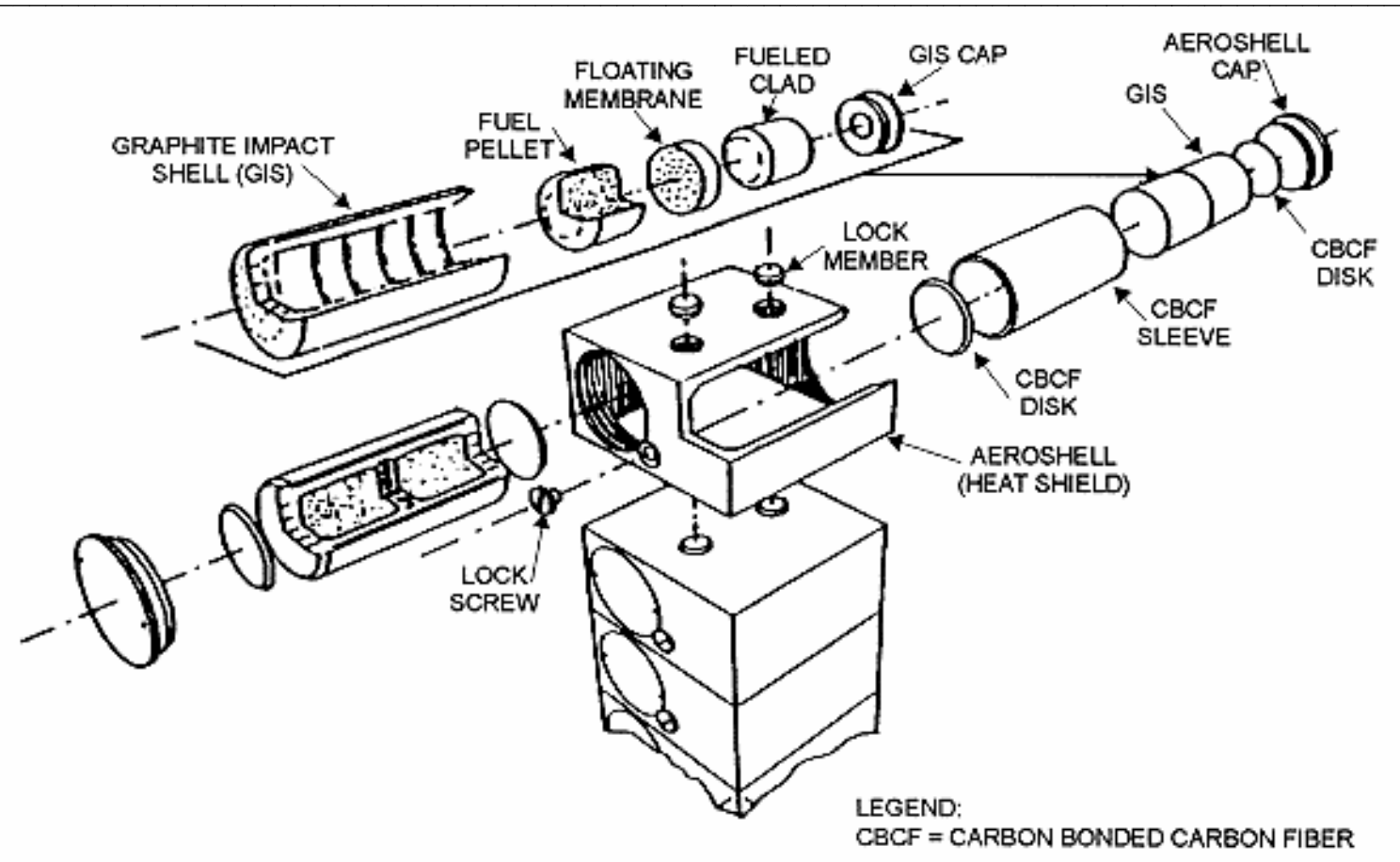

Figure 2. Exploded view of a general purpose heat source (GPHS) module. 


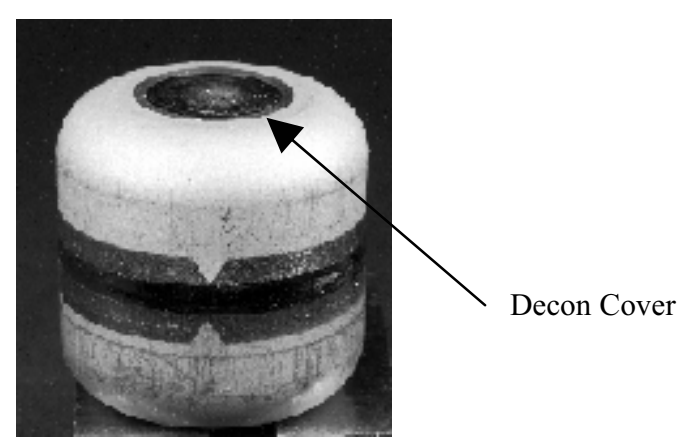

Figure 3. Fuel clad assembly.

\section{Description of New Horizons RTG Assembly and Testing Operations}

The following are descriptions of the assembly and testing operations for the New Horizons RTG that took place within the SSPSF:

\section{A. Shipping Container Containment Vessel Opening Operations}

Fuel for the RTG was shipped to the INL in multiple nested welded containers from LANL. The process of opening welded shipping container containment vessels involved a metal cutting device that is enclosed by a polycarbonate/stainless steel fume hood. Operations within the fume hood consisted of removing welded primary shipping containment vessels from welded secondary shipping containment vessels, and fuel product can containers from welded primary shipping containment vessels. The fuel product cans were then transferred to the module assembly glovebox.

\section{B. Module Assembly Operations}

Module assembly involves the opening of the fuel product cans and the assembly of eighteen (18) individual GPHS modules as shown in Figure 2. The stacking of the modules takes place in a subsequent operation. The assembly of the modules took place in the module assembly glovebox (Figure 4). This glovebox consists of two individual gloveboxes interconnected with a pass-through airlock.

The module assembly glovebox was operated under an inert argon environment and was maintained at a slight positive pressure relative to the SSPSF when assembling modules. Once the modules are assembled, they are placed into a Module Reduction Monitoring (MRM) can which was welded up in the module assembly glovebox. 


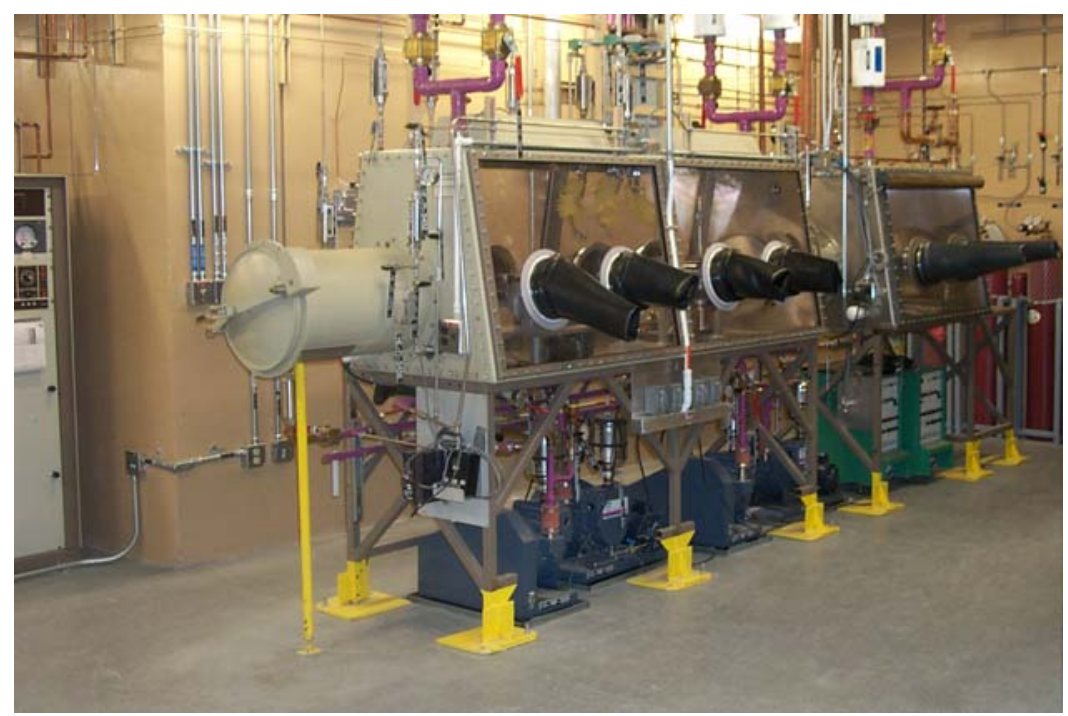

Figure 4. Module assembly glovebox system.

\section{Module Reduction Monitoring (MRM) Operations.}

Assembled GPHS modules, within their welded MRM cans were taken to the MRM room.

The function of the MRM is to permit the reduction of the $\mathrm{PuO}_{2}$ fuel to substoichiometric $\mathrm{PuO}_{1.98}$. This fuel reduction step mitigates potential thermoelectric performance degradation and enhances heat source safety performance (reduces vent plugging, migration of plutonium within the aeroshells, and iridium grain growth). This process is a very mild reduction of plutonia. Once the fuel was sufficiently reduced, the containers were backfilled with argon and manually removed from the MRM system and the cans are then transferred to the Inert Atmosphere Assembly Chamber (IAAC).

The MRM system contains a gas and vacuum manifold. This system stores and distributes ultra high purity argon gas, argon/carbon monoxide/helium gas, and vacuum through a manifold system the MRM can connection stations. This system has the capability to allow each MRM can station to be evacuated. Operator control of the manifold operation is from the computer panel located outside of the MRM, in Central Corridor 115. This allows operations personnel to remain outside of the MRM except when manually connecting or disconnecting the GPHS module containers.

\section{Inert Atmosphere Assembly Chamber Operations.}

The operations in the IAAC consisted of:

- Disassembling the MRM cans and exposing the GPHS modules (Figure (2)

- Assembling the individual modules into two individual nine pack assemblies

- Inserting the two nine pack assemblies into the RTG generator (Figure 1)

- Performing a leak check of the RTG

- Conducting initial power checks of the RTG.

The IAAC consists of two individual gloveboxes, one of which is outfitted with master/slave manipulators, interconnected by a pass through airlock. The two gloveboxes are referred to as the "opening glovebox" (Figure 5) and the "assembly/loading glovebox" (Figures 6 and 7).

The assembly of the RTG in the assembly/loading box was done with master/slave manipulators and manually with personnel using glovebox gloves.

The IAAC was maintained under an argon atmosphere at a positive pressure relative to the building. Vacuum handling tools and numerous specialized fixtures and gages were utilized during assembly operations.

All equipment in the IAAC was cleaned to meet 5 mil particle requirements.

After the initial power checks are completed, the assembly operations were complete, and the RTG was now ready for testing operations. The testing sequence was vibration testing, mass properties testing, and then thermal vacuum testing. 
In addition to the work described above, a spare RTG from a prior NASA mission was disassembled in the IAAC and the module assembly glovebox, in order to use some of the fuel for the New Horizons mission.

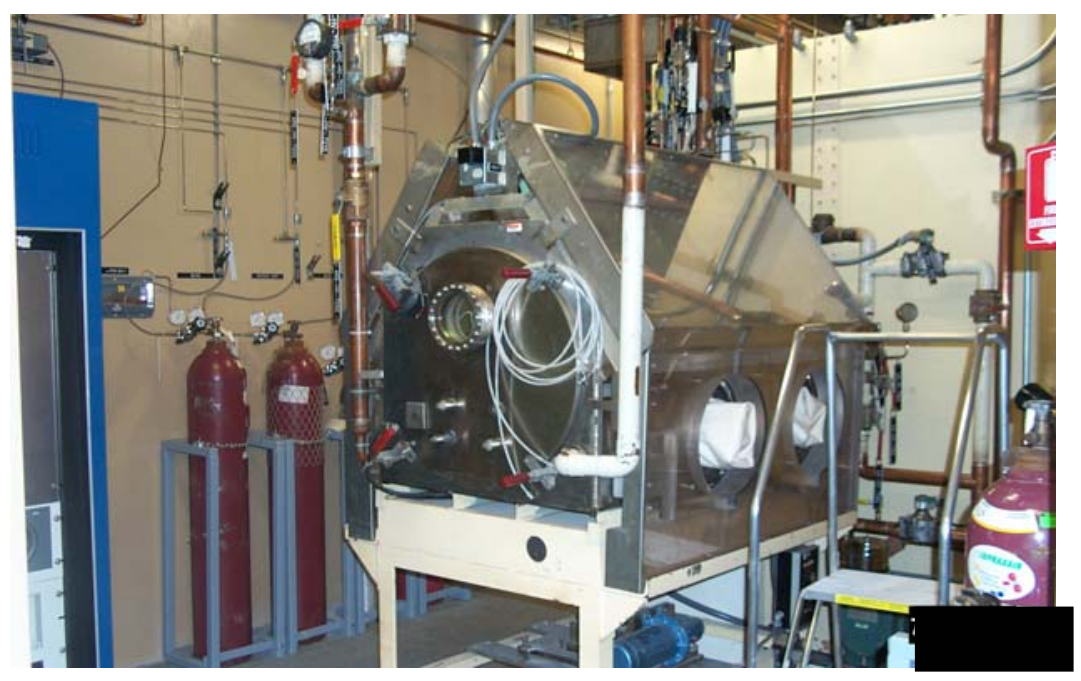

Figure 5. IAAC opening glovebox.

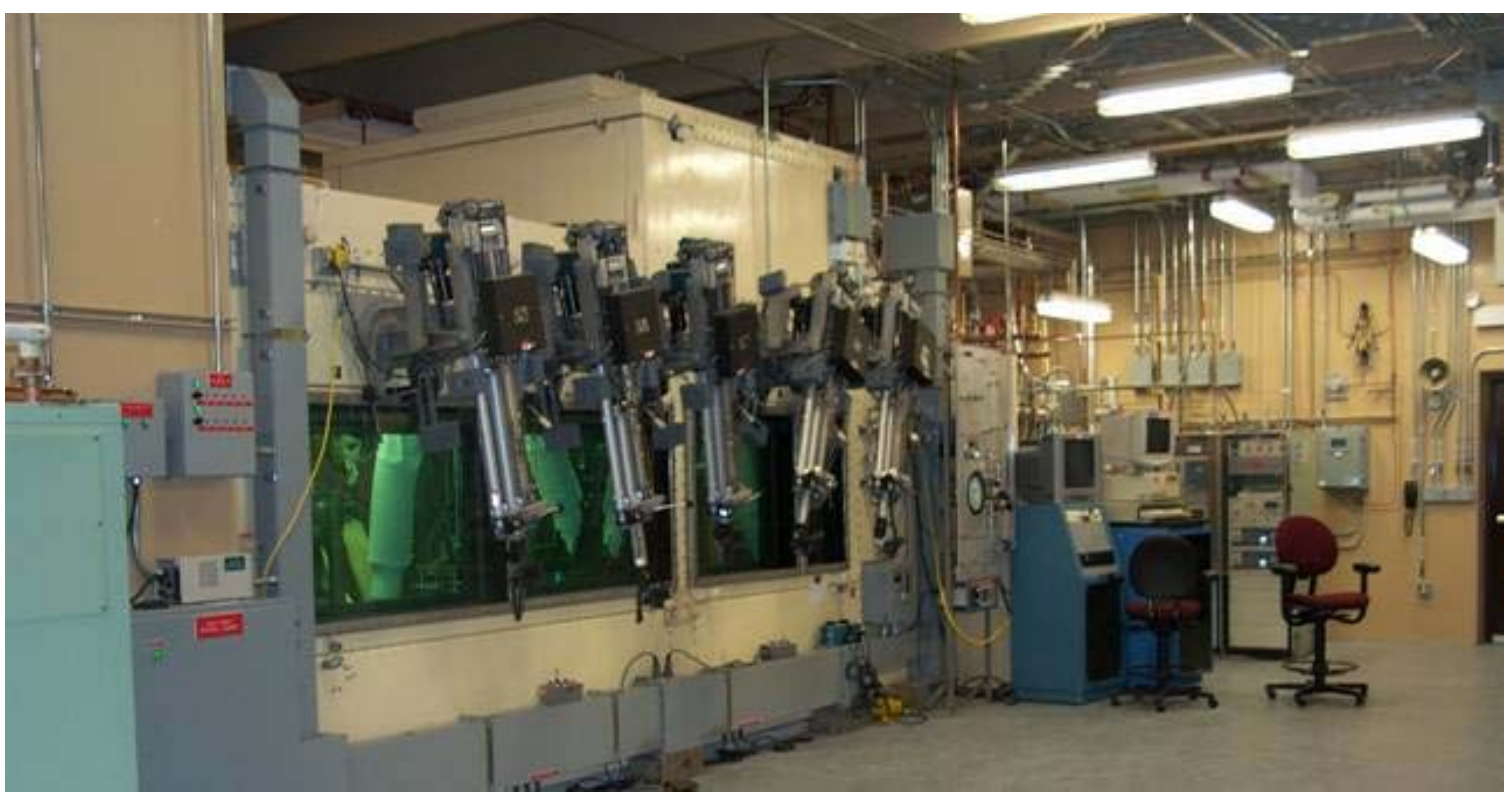

Figure 6. IAAC assembly/loading glovebox. 


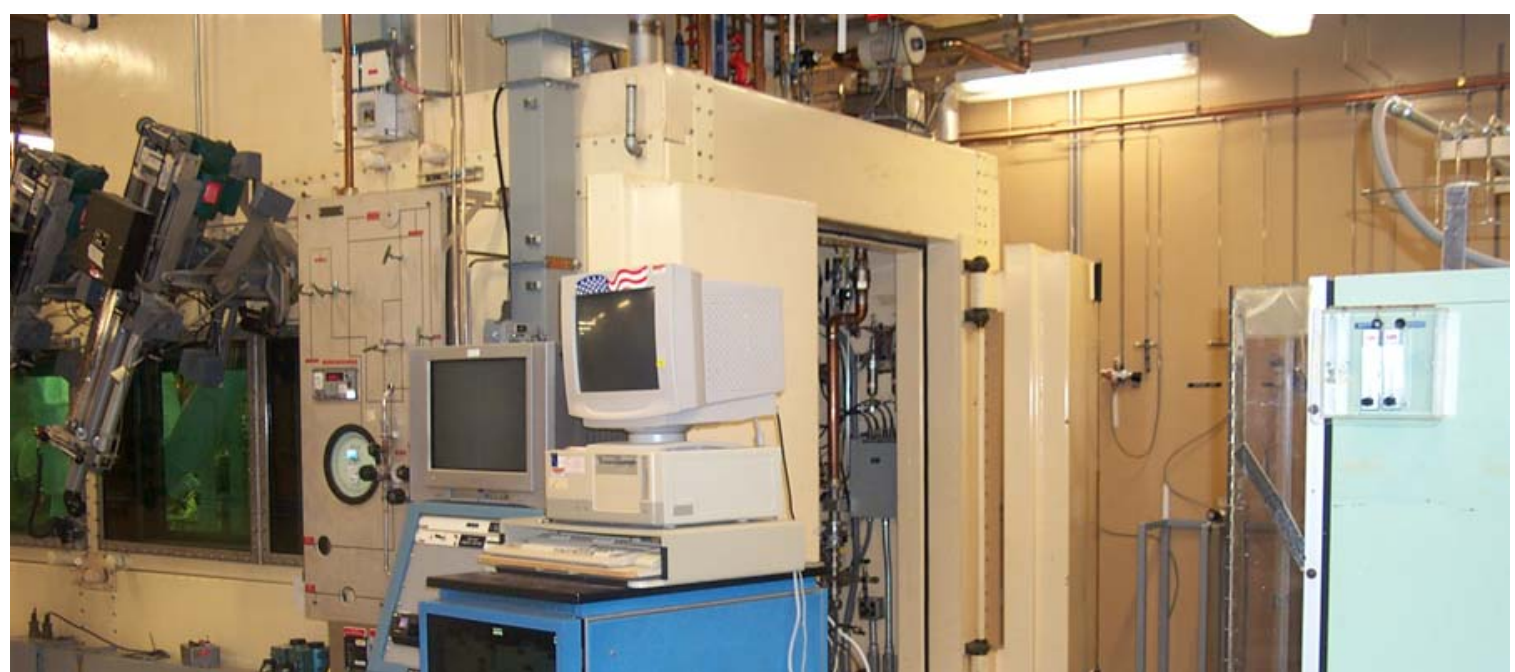

Figure 7. IAAC assembly/loading glovebox.

\section{E. Vibration Testing Operations}

The vibration testing of the RTG simulated the physical environments the RTG encountered during transport and launch environment. In order to accomplish the vibration testing, the RTG was transported into the vibration lab and transferred to the vibration table (Figure 8).

The RTG was mounted on the vibration table, instrumentation connections were made, the operating personnel left the vibration lab, and the actual test control was done from remote consoles. The power output of the RTG was monitored through a Read Out Console (ROC) during the testing.

The vibration test equipment consists of:

- Electrodynamics vibrator

- Slip table assembly, hydraulic power unit, and connecting hardware

- Mounting fixture

- Field coil power supply

- Power amplifier and transformer

- Control system

- Sensors, signal conditioners, cables, and support instrumentation.

The RTG was then transferred from the vibration lab to the mass properties testing area.

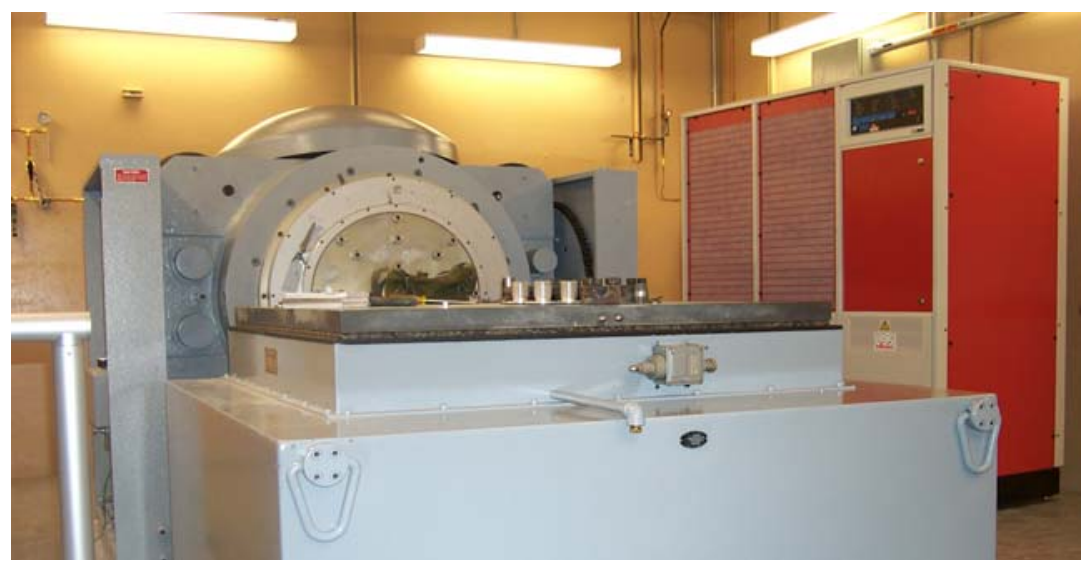

Figure 8. Vibration table.

American Institute of Aeronautics and Astronautics 


\section{F. Mass Properties Testing Operations}

The mass property equipment (Figure 9) is used to determine the center of gravity and mass of the RTG. Other properties (i.e., MOI, product of inertia) are calculated. The center of gravity tests were performed using a newly purchased mass machine. The RTG is brought into the mass properties room for testing, placed on a pre-mounted fixture on the table of the mass machine. The test was conducted from a remote console.

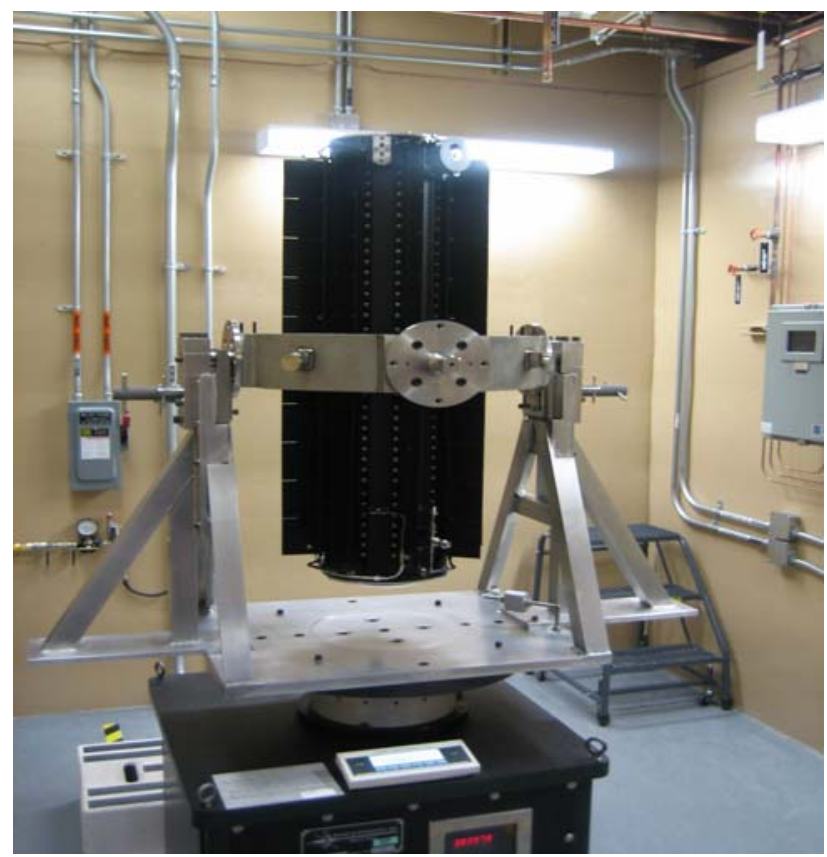

Figure 9. Mass property equipment.

\section{G. Thermal Vacuum Testing Operations}

The thermal vacuum test facility was used to evaluate the performance of the RTG in an extraterrestrial vacuum environment. The vacuum chamber (Figures 10 and 11), was equipped with various feed-throughs, including power, signal thermocouple and gas service.

The RTG was wheeled into the large vacuum chamber with a specially designed cart and attached to mounting fixtures within the chamber. The RTG was outfitted with all of the proper instrumentation. Operators sealed up the vacuum chamber and conducted the test from a remote console.

The power output of the RTG at the various conditions of thermal vacuum testing was monitored through a ROC. The vacuum chamber is approximately $1.83 \mathrm{~m}(6 \mathrm{ft})$ in diameter and $2.74 \mathrm{~m}(9 \mathrm{ft})$ long.

As reported in Reference (3), measurements of the RTG in vacuum showed BOM power was measured at 243 $\mathrm{W}$, compared with the specification requirement of $237 \mathrm{~W}$ minimum. 


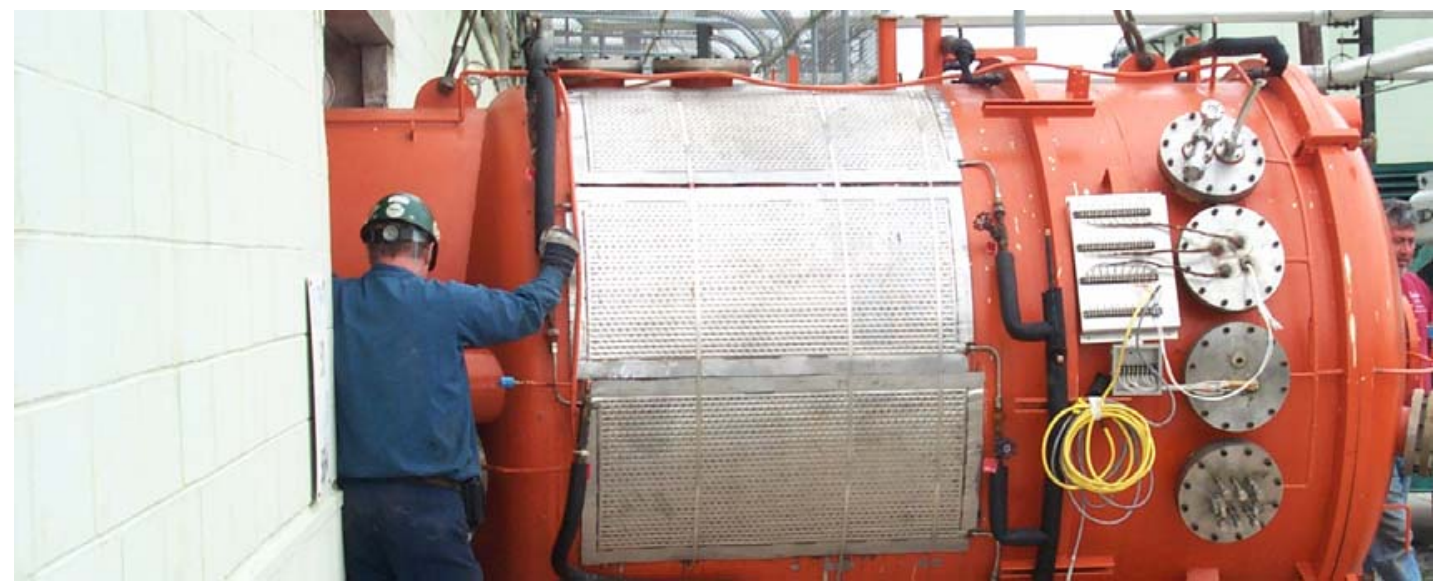

Figure 10. Thermal vacuum chamber.

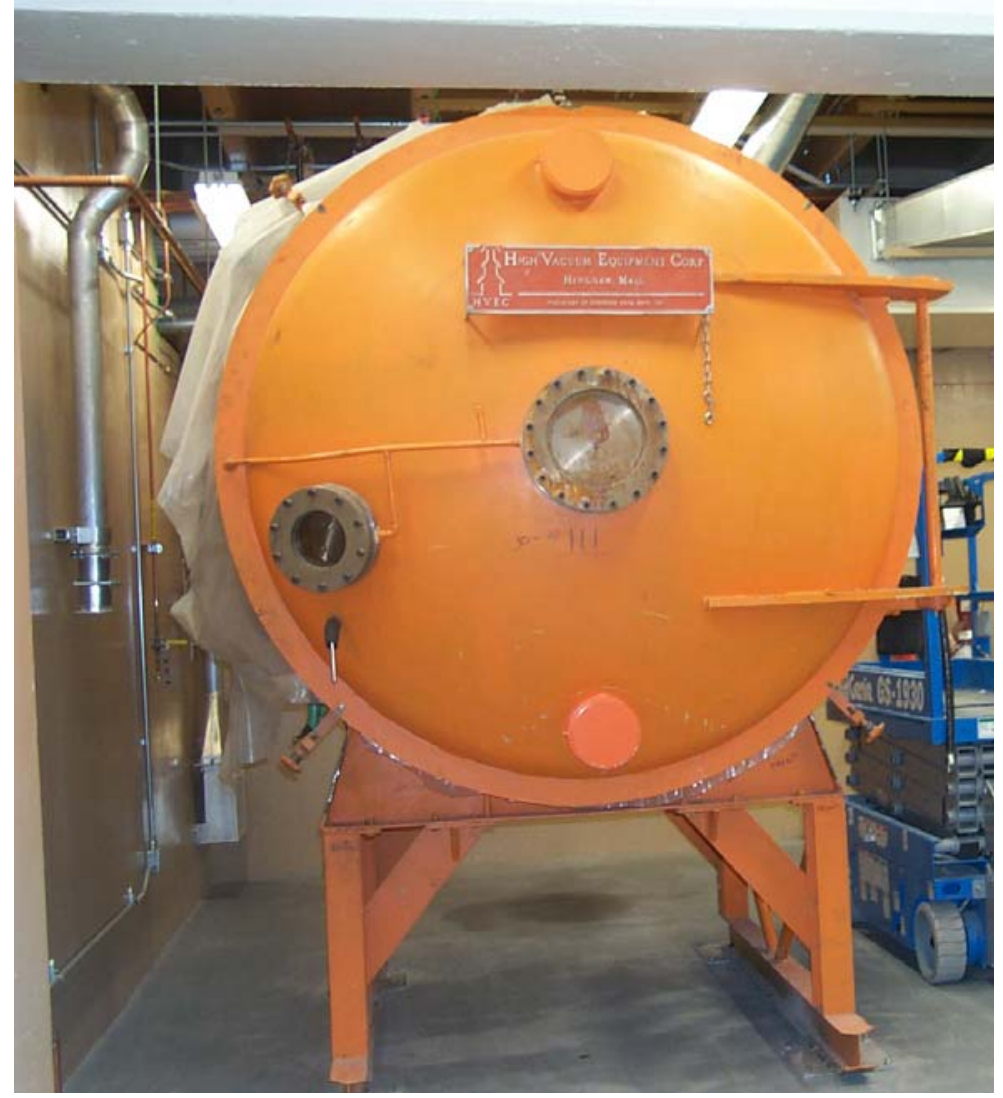

Figure 11. Thermal vacuum chamber.

\section{H. Transportation Operations}

After all testing was completed; the RTG was packaged into a Department of Transportation (DOT) certified shipping container and was then transported to the Kennedy Space Center (KSC). The INL's involvement with the RTG at KSC continued until just after launch. The New Horizons spacecraft with the RTG was successfully launched on January 19, 2006. The spacecraft will take approximately nine and a half years to reach the double planet Pluto-Charon and the Kuiper Belt. Current indications show that the RTG is functioning properly on board the spacecraft. 
An artists representation of the spacecraft is shown in Figure (12). The trajectory path of the New Horizons space craft is shown in Figure (13).

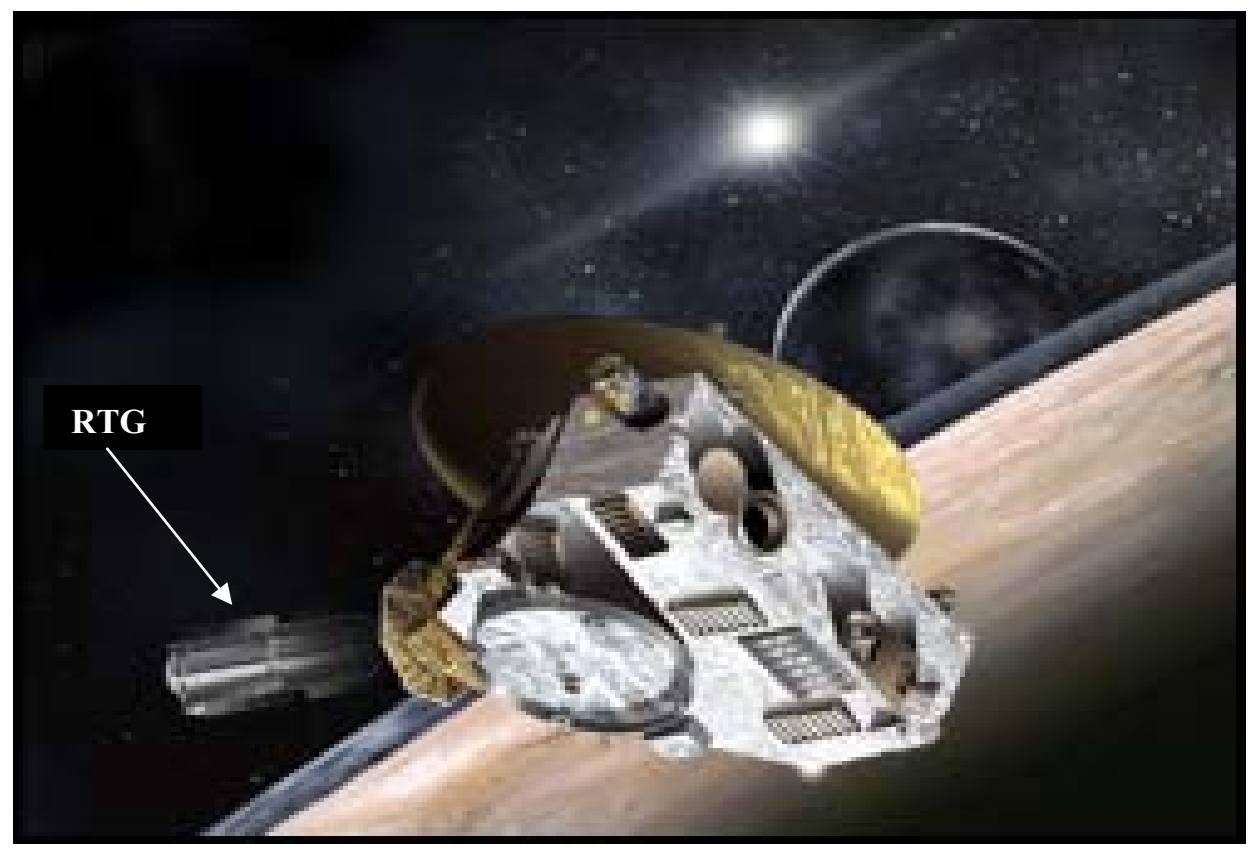

Figure 12. Spacecraft with RTG.

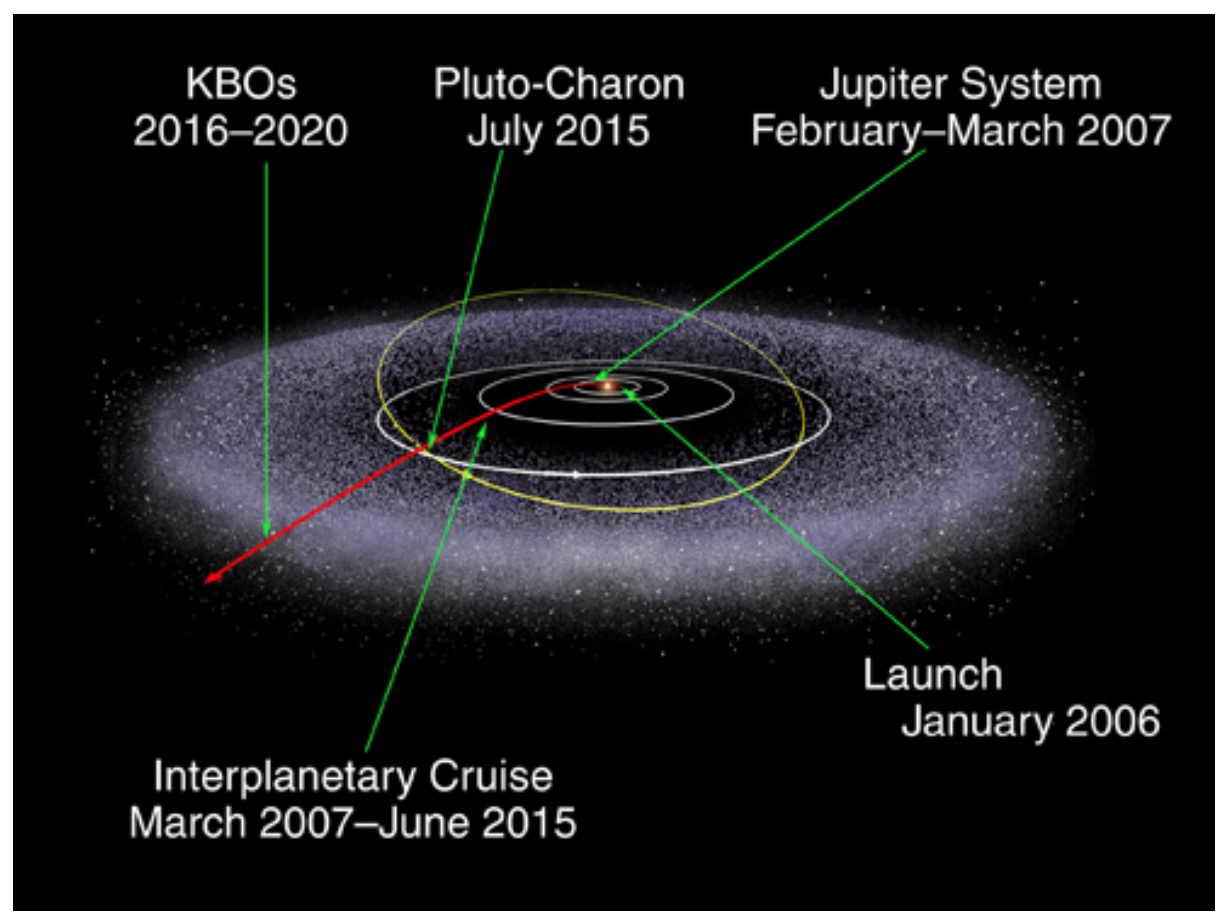

Figure 13. Trajectory path of the New Horizons space craft. 


\section{Conclusions}

The intent of this paper was to show that the INL is the home for assembling and testing of RPSs that support NASA missions. In addition, the INL assembled and tested an RTG that is now moving through space with a rendezvous with the double planet Pluto-Charon and the Kuiper Belt in approximately nine and half years.

\section{Acknowledgements}

The authors of this paper recognize the efforts by all of those who have contributed to this project. Their countless hours of hard work during regular business hours, overtime and weekends have contributed to the success of this project at the INL. This program was on a short timeline and all work was done successfully and safely.

This work was supported by the US Department of Energy, Office of Nuclear Energy under DOE Idaho Operations office contract DE-AC07-05ID14517.

\section{References}

${ }^{1}$ New Horizons Website, http://pluto.jhuapl.edu/.

${ }^{2}$ DOE-STD-1020-2002, Natural Phenomena Hazards Design and Evaluation Criteria for Department of Energy Facilities.

${ }^{3}$ Lockheed Martin Report F8 Engineering Report for the Pluto New Horizons Mission, LMSP 7330, dated November 2005. 